\section{Estudo \\ CoDebate}

em Cestão

Plamejamento
Revista Estudo \& Debate, Lajeado, v. 25, n. 1, 2018. ISSN 1983-036X

DOI: http://dx.doi.org/10.22410/issn.1983-036X.v25i1a2018.1510

\title{
ESFORÇO FISCAL E TRANSFERÊNCIA DE RECURSOS: OS EFEITOS DA RECESSÁO ECONÔMICA NA ARRECADAÇÁO DOS MUNICÍPIOS BRASILEIROS
}

\author{
Victor Godeiro de Medeiros Lima ${ }^{1}$, Roberto José Vieira de Sousa Lima², \\ Leandro Saraiva Dantas de Oliveira ${ }^{3}$
}

\begin{abstract}
Resumo: Os prefeitos responsabilizam a recente crise econômica pelo agravamento de diversos problemas que ocorrem atualmente na prestação de serviços básicos à populaçấo, atrasando, inclusive, os salários de seus servidores públicos. Alega-se que a queda nas arrecadaçôes das receitas é a responsável pela incapacidade em fazer jus às obrigaçôes financeiras. Com isso, o presente estudo tem como objetivo analisar a composição das receitas arrecadadas pelos municípios brasileiros no período de 2013 a 2015.Em virtude da incipiente literatura que versem sobre a crise econômica brasileira recente, o estudo se baseou em artigos científicos que abordam a composição das receitas arrecadadas pelos municípios. A pesquisa é descritiva e qualitativa e possui 88 municípios brasileiros em sua amostra, divididos em dois grupos: o Grupo A, que consiste em 44 municípios de maior Produto Interno Bruto (PIB); e o Grupo B, que consiste em 44 municípios de menor PIB. Coletouse dados sobre as receitas próprias e de transferências correntes. Através da análise dos dados, constatou-se que os municípios do Grupo B são mais dependentes das transferências correntes (em média, 95\%), enquanto os municípios do Grupo A dependem de forma equânime das receitas próprias e de transferência. A crise econômica afetou negativamente as receitas de transferência, que apresentaram uma queda de $7,2 \%$ no período analisado, enquanto as receitas próprias aumentaram em 5,68\%. O estudo não encontra respaldo para o conceito de preguiça fiscal quando demonstra que os municípios do Grupo B aumentaram suas receitas próprias, demonstrando esforço fiscal.
\end{abstract}

Palavras-chave: Receita pública. Crise econômica. Preguiça Fiscal.

1 Doutorando em Ciências Contábeis da Universidade de Brasília (UnB). Bacharel (UFRN) e Mestre (UnB/ UPFB/UFRN) em Ciências Contábeis.

2 Bacharel (UFPE) e Mestre (UnB/UFPB/UFRN) em Ciências Contábeis. Professor de Ciências Contábeis da UNIRN e UFRN em Natal/RN.

3 Bacharel (UFRN) e Mestre (UnB/UFPB/UFRN) em Ciências Contábeis. Graduado em Administração Pública (UFRN). Professor Efetivo de Contabilidade Governamental da UFCA. 


\title{
FISCAL EFFORT AND TRANSFER OF RESOURCES: THE EFFECTS OF THE ECONOMIC RECESSION ON THE COLLECTION OF BRAZILIAN MUNICIPALITIES
}

\begin{abstract}
The mayors blame the recent economic crisis for the aggravation of several problems that currently occur in theprovisionofbasicservicesto thepopulation, evendelayingthesalariesoftheirpublicservants. It isalleged that thefall in revenue collections is responsible for the inability to live up to financial obligations. Thus, the present study aims to to analyze the composition of the revenues collected by the Brazilian municipalities in the period from 2013 to 2015.Due to the lack of literature that investigates the recent Brazilian economic crisis, the study was based on papers that discuss the composition of revenues collected by municipalities. The research is descriptive and qualitative and has 88 Brazilian municipalities in its sample, divided into two groups: Group A, that's composed of 44 municipalities with the highest GDP and Group B that's composed of 44 municipalities with the lowest GDP. Data were collected on directly collected and transfered revenues. By analyzing the data, it was found that Group B municipalities depend more on current transfers (on average, 95\%), while Group A depend more equitably on directly collected and transfered revenues. The economic crisis negatively impacted transfer revenues, which fell by $7.2 \%$ in the analyzed period, while directly collected revenues increased by $5.68 \%$. The study does not find support for the concept of fiscal laziness when it demonstrates that municipalities of Group $B$ increased their own revenues, demonstrating fiscal effort.
\end{abstract}

Keywords: Public revenue. Economic crisis. Fiscal Laziness.

\section{Introdução}

O Brasil atualmente enfrenta uma de suas maiores recessóes econômicas pós-Plano Real fazendo com que alguns municípios se deparem com problemas em arcar com suas despesas devido ao decréscimo em arrecadaçáo de receitas. Pelo menos é o que alguns prefeitos alegam, dizendo enfrentar problemas para arcar com despesas básicas de manutenção dos municípios, inclusive com casos de atraso dos salários dos servidores municipais (AYER, 2017).

As fontes de receitas de um município são basicamente duas: fontes próprias, ou seja, decorrentes diretamente do esforço do município em arrecadá-las como, por exemplo, Imposto Sobre Serviços de Qualquer Natureza (ISS) e Imposto Predial e Territorial Urbano (IPTU); e decorrentes de transferências de outras entidades federativas, como o Fundo de Participação dos Municípios (FPM) e o Imposto Sobre a Circulação de Mercadorias e Serviços (ICMS).

Mattos, Rocha e Arvate (2011) ressaltam que a principal fonte de sustento dos municípios se encontra no FPM. Um município que depende em substancialmente de apenas uma dessas fontes de recurso se mostra mais vulnerável às mudanças prejudiciais no cenário econômico, o que o colocará em uma posição desfavorável para fazer jus aos seus compromissos financeiros, portanto, desejável uma arrecadação equilibrada para preservar a saúde financeira.

Considerando que a crise financeira prejudica os recursos transferidos de outros entes para os municípios, espera-se que o Chefe do Poder Executivo Municipal, , visando garantir o equilíbrio das finanças municipais, tribute mais e/ou busque novas maneiras de arrecadar recursos de seus cidadãos. 
Nesse pensamento, visando verificar como e se a crise econômica atingiu os municípios brasileiros e suas arrecadaçóes de receitas, elaborou-se o seguinte problema de pesquisa: quais os efeitos da crise econômica brasileira na arrecadação e composiçáo de receitas dos municípios?Para responder ao problema de pesquisa, propóe-se como objetivo geral analisar a composição das receitas arrecadadas pelos municípios brasileiros no período de 2013 a 2015, observando como a crise econômica as influenciou.

Esse estudo se justifica na necessidade de se discutir como a crise econômica repercutiu na gestão financeira dos municípios e se os gestores públicos estão conseguindo preservar o poder aquisitivo. Pretende-se perceber se as prefeituras estấo elevando a carga tributária para garantir um nível ideal de receitas e se as transferências de recursos foram de fato afetadas. Convém destacar também quais prefeituras aumentaram significativamente a receita arrecadada para possibilitar estudos de caso futuros de forma específica para compreender que medidas foram adotadas, utilizando-as como benchmarking às demais, além de destacar quais prefeituras se encontram na outra ponta do espectro, apresentando resultados negativos, como forma de estudar quais os problemas enfrentados e escolhas políticas realizadas as levaram aos resultados percebidos.

Utiliza-se como base os estudos de Massardi e Abrantes (2016), que verificaram qual a dependência dos municípios mineiros especificamente quanto ao FPM no exercício de 2004 a 2009, trazendo um enfoque nas receitas de transferência; e Siqueira (2014), que analisou a eficiência tributária dos municípios pernambucanos, dando ênfase às receitas próprias.

\section{Revisão de Literatura}

\subsection{Organizaçáo Político-Administrativa dos Municípios}

A Constituição da República de 1988 adotou para o Brasil o Federalismo Fiscal, onde os municípios são retratados como entidades autônomas, possuindo constituiçốes próprias - chamadas de leis orgânicas - e arrecadando alguns tributos diretamente (SELCHER, 1998; WATTS, 1998).

Apesar disso, os municípios brasileiros dependem principalmente dos recursos transferidos de outros entes para manter o equilíbrio fiscal, o que diminui a discricionariedade dos prefeitos no gasto dos recursos da Prefeitura (BOHTE, 2001) e obriga uma relação amigável com outros políticos para manter o fluxo financeiro (GOMES; ALFINITO; ALBUQUERQUE, 2013).

Ademais, segundo Mouritzen e Svara (2002), adotou-se o formato strong-mayor (ou prefeito-forte, em tradução livre), em que o prefeito possui uma variedade de atribuiçóes, entre elas: agir como líder político; gestor de recursos; estabelecer contatos com a Câmara Legislativa para enviar e aprovar leis; e negociar com o Estado e União para coletar mais recursos. 


\subsection{Crise Econômica Recente e Arrecadação de Receitas}

A desaceleração do crescimento do PIB brasileiro desencadeada a partir do ano de 2014 ocasionou um impacto na atividade econômica do país repercutindo em variáveis diversas como crédito, investimento, renda e emprego da população de forma geral, repercutindo de forma negativa na demanda pelos diversos setores produtivos do país (SOUZA; REGO, 2016).

No ano de 2015, o PIB do Brasil caiu -3,85\% comparado com 2014. É a pior variação no período 1985-2015 (FIGURA 1) e, segundo Pires (2016), o triênio 2014-2016 corresponde a mais grave recessão econômica a atingir o Brasil, demonstrada na Figura abaixo

Figura 1 - Variaçóes do PIB brasileiro de 1986 a 2015

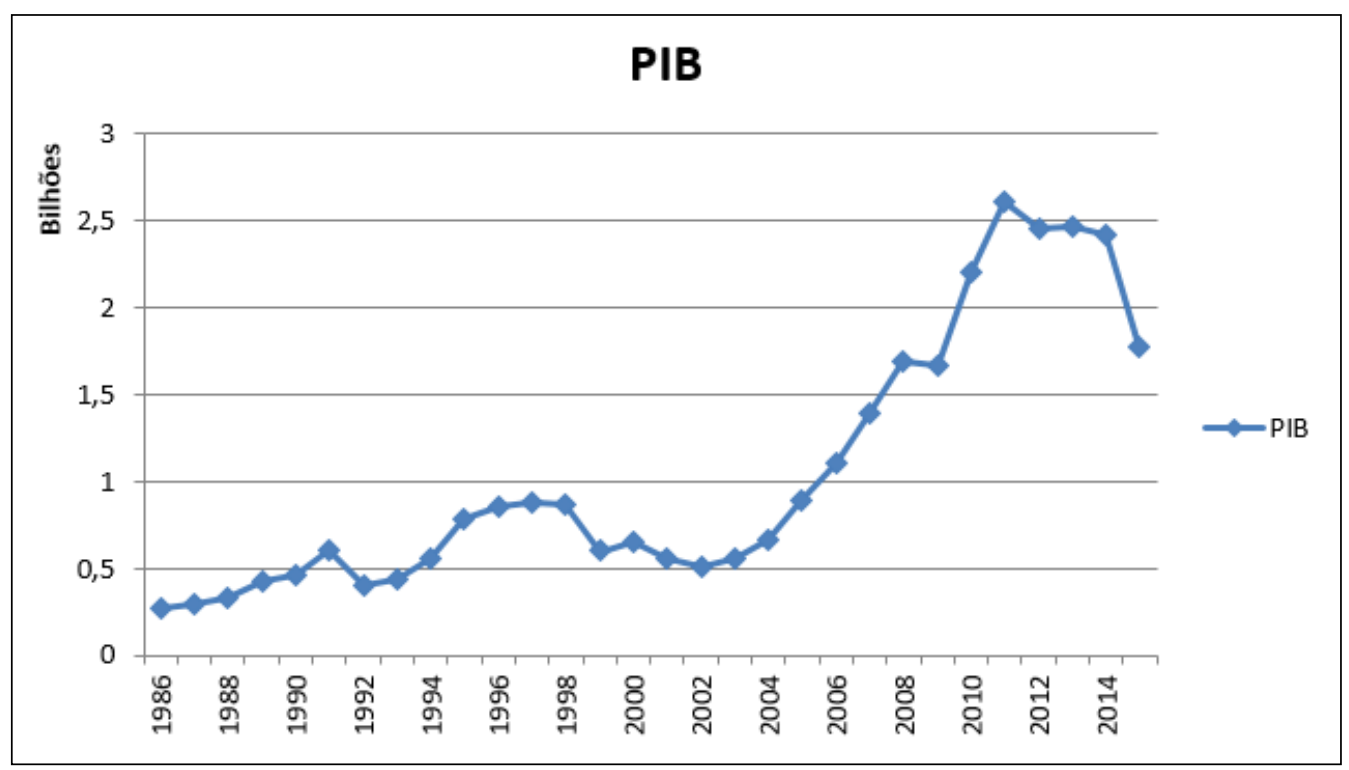

Fonte: Elaboração com dados do Banco Mundial (2017).

$\mathrm{Na}$ análise da Figura 1 percebe-se que o ano de 2015 apresentou um PIB mais baixo do que o registrado 5 anos atrás, em 2010. Levando em consideraçáo que a tributação pelo Estado é impactada diretamente pela saúde econômica do país, sendo prejudicada em caso de recessão (MASSARDI; ABRANTES, 2015), infere-se que os municípios devem experimentar problemas em arrecadar receitas, sejam elas de arrecadação própria, por exemplo, o ISS; ou receitas de transferências de outros entes, por exemplo, o ICMS; transferido diretamente pelo estado aos municípios - ambas as receitas afetadas intimamente pelas mudanças no mercado.

Com a necessidade de manter a estrutura administrativa da prefeitura e os serviços básicos à população, o prefeito deverá garantir um nível satisfatório de receitas para fazer face às despesas. Há uma tendência dos gestores públicos municipais optarem por financiar os bens públicos com recursos de terceiros - ou seja, recursos de transferências - em 
detrimento de recursos tributários próprios, já que tributar os munícipes sob sua gestão gera custo político indesejado (COSSIO, 1995; TRISTÃO, 2003).

Nesse raciocínio, se percebe uma tendência dos prefeitos não buscarem arrecadar mais receitas próprias, preferindo transferências governamentais, principalmente em municípios que destas mais dependem (RIBEIRO; SHIKIDA, 2000; VESCOVI JÚNIOR, 2003; RODRIGUES, 2004; MORGUES; BENIN, 2012).

Orair e Alencar (2010) enfatizam que a literatura denomina esse fenômeno de preguiça fiscal. Os autores argumentam que o alto nível de transferências se reflete em uma ineficiência em arrecadar recursos, além de afirmar que as transferências são utilizadas como instrumento de barganha política.

Apesar da suposta preferência em arrecadar receitas de transferências - inclusive em períodos de crise econômica - pelo seu baixo custo político, a principal ferramenta disponível para o prefeito garantir uma arrecadaçáo suficiente para fazer face às despesas é buscar novos meios de arrecadar receitas próprias. Isso é desejável também, pois Mattos, Rocha e Arvate (2011) afirmam que as gestôes tendem a gastar de forma mais ineficiente o recurso arrecadado através de transferências - esse fenômeno é chamado de fypaper effect.

Essa ideia é respaldada pelo estudo de Zafra-Goméz, López-Hernández e HernándezBastida (2009), pois asseveram que a saúde financeira de um município está atrelada à sustentabilidade, flexibilidade e vulnerabilidade. Este último estaria atrelado especificamente ao nível de dependência de uma organização em recursos externos, seja por transferências ou garantias, ou seja, é recomendável a um município manter sua vulnerabilidade em níveis mínimos, dependendo menos de transferências de outros entes.

\section{Metodologia}

\subsection{Delineamento da Pesquisa}

A classificado desta pesquisa quanto aos objetivos, a pesquisa é descritiva, pois visa descrever características de determinada população; quanto aos procedimentos, a pesquisa é bibliográfica, pois buscará explicar um problema a partir de referenciais teóricos publicados em documentos; e quanto à abordagem do problema, o estudo é qualitativo.

Os dados utilizados são secundários, portanto, optou-se por coletá-los diretamente no site da Secretaria do Tesouro Nacional (SECRETARIA DO TESOURO NACIONAL, 2017). Foram coletados dados referentes aos exercícios 2013, 2014 e 2015 quanto às receitas próprias (englobando as receitas tributárias, de serviço e patrimoniais) e as receitas de transferências correntes.

Para permitir uma análise comparativa entre os anos, corrigiram-se os valores pelo Índice Nacional de Preços ao Consumidor Amplo (IPCA), calculado pelo [descrever por extenso] (IBGE). Danda, Queiroz e Hoffman (2016)justificam o uso do IPCA por se tratar de índice oficial do governo federal para medição de metas inflacionárias. Os dados coletados em 2013, foram corrigidos em 17,08\%, já para o exercício de 2014, em 10,67\%. 
Os softwares Microsoft Excel ${ }^{\circ}$ e o $I B M S^{\circ} P S S^{\circ}$, versão 21, foram utilizados para tabulação e análise dos dados. O IBM SPSS ${ }^{\oplus}$ foi utilizado especificamente para elaborar a Tabela 2 e as Figuras 2 e 3 que correspondem à estatística descritiva da amostra por Grupos, enquanto o Microsoft Excel $^{\circ}$ foi utilizado para os demais cálculos.

Para a análise realizada na estatística descritiva, calculou-se a participação percentual das receitas próprias e das receitas de transferências correntes frente ao total de receitas correntes arrecadas pelos municípios. Já para o restante da análise de dados, utilizaram-se valores numéricos corrigidos pelo IPCA da média dos municípios integrantes para realizar as análises verticais e horizontais dos dados.

Enquanto à limitação do estudo, os dados analisados não contemplam toda a gama de receitas dos municípios analisados, já que estes podem apresentar receitas de capital e intraorçamentárias, por exemplo. Espera-se que estas sejam de menor significância, principalmente nos municípios do Grupo B.

\subsection{Amostra}

Como base para seleção da amostra, argumenta-se que quanto mais frágil for a economia de um município, maior tende a ser sua dependência de recursos de transferências. (MATTOS; ROCHA; ARVATE, 2011) Sendo assim, investigou-se como a crise econômica afetou a arrecadação dos municípios pertencentes a dois grupos distintos de municípios: o primeiro grupo é composto pelos 50 municípios que apresentam maiores PIBs - denominado Grupo A - e o segundo grupo será composto pelos 50 municípios que apresentam os PIBs mais baixos do país - denominado Grupo B.

Os municípios foram selecionados de acordo com os dados disponibilizados pelo IBGE referentes a 2013 onde são elencados todos os municípios brasileiros com os seus PIBs estimados para o ano. O número de 100 municípios para a amostra se deu por conveniência dos pesquisadores. 


\begin{tabular}{|c|c|}
\hline Grupo A - Municípios de Maiores PIBs & Grupo B - Municípios de Menores PIBs \\
\hline $\begin{array}{l}\text { São Paulo (SP), Rio de Janeiro (RJ), Belo } \\
\text { Horizonte (MG), Curitiba (PR), Manaus (AM), } \\
\text { Campos dos Goytacazes (RJ), Porto Alegre (RS), } \\
\text { Osasco (SP), Salvador (BA), Campinas (SP), } \\
\text { Fortaleza (CE), Garulhos (SP), São Bernardo do } \\
\text { Campo (SP), Recife (PE), Barueri (SP), Goiânia } \\
\text { (GO), Jundiaí (SP), São José dos Campos (SP), } \\
\text { Sorocaba (SP), Uberlândia (MG), Belém (PA), } \\
\text { São José dos Pinhais (PR), Duque de Caxias (RJ), } \\
\text { Santo André (SP), Contagem (MG), Ribeirão } \\
\text { Preto (SP), Sáo Luis (MA), Betim (MG), Vitória } \\
\text { (ES), Joinville (SC), Caxias do Sul (RS), Campo } \\
\text { Grande (MS), Piracicaba (SP), Parauapebas (PA), } \\
\text { Natal (RN), Niterói (RJ), Santos (SP), Macaé } \\
\text { (RJ), Cuiabá (MT), Cabo Frio (RJ), Maceió } \\
\text { (AL), Londrina (SC), Serra (ES), Itajaí (SC), São } \\
\text { Caetano do Sul (SP), Taubaté (SP), Rio das Ostras } \\
\text { (RJ), Joáo Pessoa (PB), Teresina (PI), Camaçari } \\
\text { (BA) }\end{array}$ & $\begin{array}{l}\text { Pajeú do Piauí (PI), Taipas do Tocantins (TO), Barreiras } \\
\text { do Piauí (PI), Oliveira de Fátima (TO), Curralinhos } \\
\text { (PI), Antônio Prado de Minas (MG), Cajazeiras do Piauí } \\
\text { (PI), Belém do Piauí (PI), Curral Velho (PB), São Félix } \\
\text { do Piauí (PI), Olaria (MG), Novo Santo Antônio (PI), } \\
\text { Mato Grosso (PB), Senador Cortes (MG), Tanque do } \\
\text { Piauí (PI), Amparo (SP), Vera Mendes (PI), Passabém } \\
\text { (MG), Riacho de Santo Antônio (PB), Chapada de } \\
\text { Areia (TO), Rio da Conceiçáo (TO), São Miguel do } \\
\text { Fidalgo (PI), João Costa (PI), Pedro Laurentino (PI), } \\
\text { Floresta do Piauí (PI), Areia de Baraúnas (PB), Cedro do } \\
\text { Abaeté (MG), Serra da Saudade (MG), Quixabá (PB), } \\
\text { Tamboril do Piauí (PI), Anhanguera (MT), São Félix do } \\
\text { Tocantins (TO), Araguainha (MT), Parari (PB), São José } \\
\text { do Brejo do Cruz (PB), Francisco Macedo (PI), Zabelê } \\
\text { (PB), São Miguel da Baixa Grande (PI), Olho D'Água } \\
\text { do Piauí (PI), Coxixola (PB), Lagoinha do Piauí (PI), } \\
\text { Viçosa (MG), São Luis do Piauí (PI), Santo Antônio dos } \\
\text { Milagres (PI) e Miguel Leáo (PI). }\end{array}$ \\
\hline
\end{tabular}

Fonte: IBGE (2013).

Por limitaçóes nos dados disponibilizados pelos municípios para a STN, alguns municípios foram retirados da amostragem: Campos dos Goytacazes (RJ); Duque de Caxias (RJ); São Luís (MA); Macaé (RJ); Cabo Frio (RJ); e João Pessoa (PB) do Grupo A; São Sebastiāo do Rio Preto (MG); Paiva (MG); Prata do Piauí (PI); Anhanguera (GO); Aroeiras do Itaim (PI) e São Domingo do Cariri (PB) do Grupo B. Ao final, restaram 44 municípios de cada grupo, totalizando uma amostra de 88 municípios.

\section{Análise dos Dados}

\subsection{Estatística Descritiva}

A Tabela 2 apresenta a estatística descritiva dos dados dos municípios selecionados na amostra quanto à média de arrecadação de receitas próprias e de transferências em comparação com as receitas correntes. 
Tabela 2 - Estatística descritiva dos municípios do Grupo A e B

\begin{tabular}{c|c|c|c|c|c|c|c}
\hline \multirow{2}{*}{ Grupo } & Tipo de Receita & Mínimo & Máximo & Média & $\begin{array}{c}\text { Desvio- } \\
\text { Padrão }\end{array}$ & Assimetria & Curtose \\
\hline \multirow{2}{*}{ Grupo A } & Receitas Próprias & $17 \%$ & $58 \%$ & $37,75 \%$ & $9,95 \%$ & 0,044 & $-0,602$ \\
\cline { 2 - 8 } & Receitas de Transf. & $39 \%$ & $91 \%$ & $61,52 \%$ & $11,2 \%$ & 0,286 & 0,122 \\
\hline \multirow{2}{*}{ Grupo B } & Receitas Próprias & $1 \%$ & $27 \%$ & $3,77 \%$ & $4,9 \%$ & 3,948 & 15,954 \\
\cline { 2 - 8 } & Receitas de Transf. & $63 \%$ & $99 \%$ & $95,16 \%$ & $6,5 \%$ & $-3,98$ & 16,967 \\
\hline
\end{tabular}

Fonte: Elaborado pelos próprios autores.

A Tabela 2 demonstra que os municípios do Grupo A apresentam uma menor dependência das receitas de transferência $(61,52 \%)$ do que os municípios do Grupo B $(95,16 \%)$. Entretanto, convém apontar que ambos os grupos dependem das transferências correntes como principal fonte de renda para manter suas operaçóes. Apenas quatro municípios pertencentes à amostra demonstraram arrecadar mais receitas próprias do que de transferência: São Paulo (SP); Rio de Janeiro (RJ); Curitiba (PR); e Porto Alegre (RS).

Objetivando analisar os desvios-padrão, coeficientes de assimetria e curtose, apresenta-se os histogramas do Grupo A, tanto para receitas próprias, como para receitas de transferências (FIGURA 2).

Figura 2 - Histogramas do Grupo A - Receitas Próprias e de Transferências

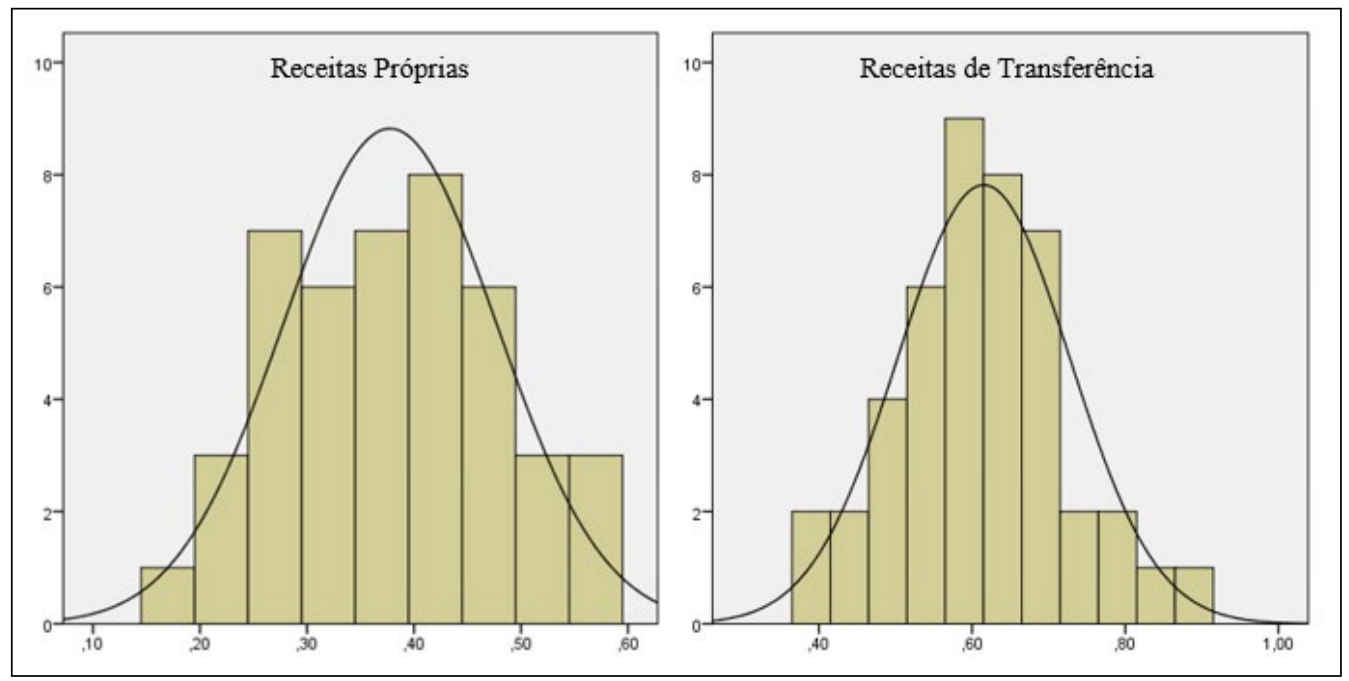

Fonte: Elaborado pelos próprios autores.

Uma distribuição deve ser considerada substancialmente assimétrica se o coeficiente de assimetria apresentar valores inferiores a -1 e superiores a 1 (HAIR et al., 2005). Portanto, o Grupo A encontra-se em parâmetros aceitáveis. Entretanto, os dados do Grupo $\mathrm{B}$ apresentam realidade distinta. 
O Grupo B apresenta coeficientes consideravelmente distantes do desejável (FIGURA 3). Isso aponta para um padrão na amostra, demonstrando que os municípios do Grupo $\mathrm{B}$ enfrentam as mesmas condiçóes no que tange à arrecadação de receitas, enquanto os municípios do Grupo A apresentam características diferentes, com um desvio-padrão mais acentuado.

Figura 3 - Histogramas do Grupo B - Receitas Próprias e de Transferências

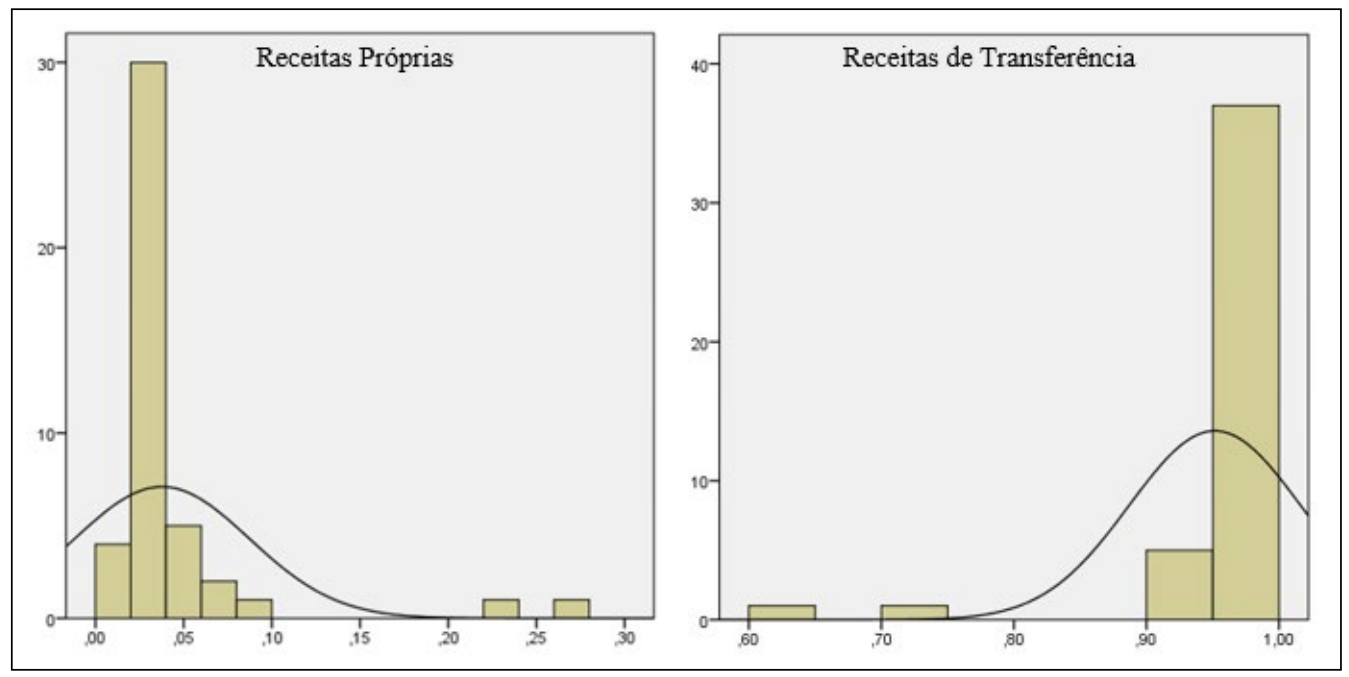

Fonte: Elaborado pelos próprios autores.

Quanto ao coeficiente de curtose, Casella e Berger (2010) apontam que um valor superior a 3 representa uma curva muito aguda, o que pode ser observado nos histogramas do Grupo B (FIGURA 3). Esse pico representa uma concentração dos dados na amostra, o que corrobora com a não-normalidade da distribuição.

A análise do nível de dependência dos municípios quanto às transferências correntes e sua relação com o número de habitantes (FIGURA 4). 
Figura 4 - Correlação entre Transferências Correntes e Número de Habitantes

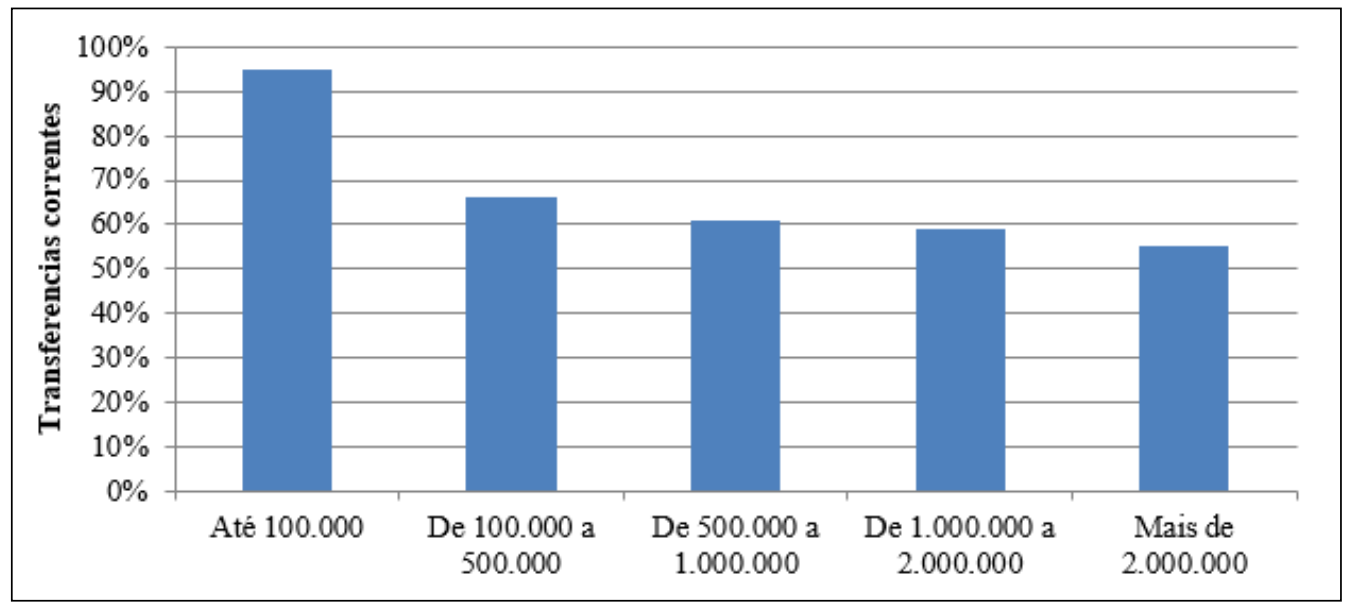

Fonte: Elaborado pelos próprios autores.

Apesar do número de municípios da amostra impedir inferências adicionais, os resultados corroboram com o estudo de Vescovi Júnior (2003) ao demonstrar que há uma tendência em um município depender mais das transferências correntes do Estado e da União quanto menor for o seu número de habitantes. Um padrão similar foi encontrado no estudo de Massardi e Abrantes (2016), que observaram que os municípios com menos de 20.000 habitantes possuem em média elevada dependência de FPM e consequentemente de transferências correntes.

A Figura 3 encontra respaldo nos achados de Nascimento (2010) quando argumenta que quanto menor o município, maior tende a ser a representatividade das receitas de transferências, já que elas provocam um efeito desestimulante na arrecadaçáo. Esse mesmo efeito foi observado por Massardi e Abrantes (2016).

\subsection{Efeitos da Crise Econômica na Arrecadaçáo dos Municípios}

Nesta subseção analisa-se como a crise econômica afetou a arrecadação das receitas próprias e de transferência, sendo assim, comparou-se a arrecadação dos exercícios 2013, 2014 e 2015 corrigidos pelo IPCA para o Grupo A e o Grupo B (TABELA 3). 
Tabela 3 - Análise horizontal das variações nas arrecadações dos municípios do Grupo A (Média)

\begin{tabular}{c|c|c|c|c|c|c}
\hline $\begin{array}{c}\text { Tipo de } \\
\text { Receita }\end{array}$ & Exercício 2013 & $\%$ & Exercício 2014 & $\%$ & Exercício 2015 & $\begin{array}{c}\text { Variaçáo } \\
\% \text { 2013- } \\
\mathbf{2 0 1 5}\end{array}$ \\
\hline $\begin{array}{c}\text { RECEITAS } \\
\text { PRÓPRIAS }\end{array}$ & $\mathbf{1 . 6 1 2 . 0 9 2 . 4 1 6 , 0 8}$ & $+\mathbf{7 , 7 9 \%}$ & $\mathbf{1 . 7 3 7 . 6 2 2 . 0 7 4 , 5 8}$ & $-\mathbf{1 , 9 7 \%}$ & $\mathbf{1 . 7 0 3 . 3 4 1 . 5 4 3 , 3 9}$ & $+\mathbf{5 , 6 6 \%}$ \\
\hline $\begin{array}{c}\text { Receita } \\
\text { Tributária }\end{array}$ & $1.420 .746 .972,76$ & $+5,42 \%$ & $1.497 .702 .506,40$ & $-3,95 \%$ & $1.438 .530 .949,97$ & $+1,25 \%$ \\
\hline $\begin{array}{c}\text { Receita } \\
\text { Patrimonial }\end{array}$ & $89.702 .068,94$ & $+56,72 \%$ & $140.583 .689,93$ & $+23,12 \%$ & $173.085 .506,23$ & $+92,95 \%$ \\
\hline $\begin{array}{c}\text { Receita de } \\
\text { ServiçOS }\end{array}$ & $101.643 .374,38$ & $-2,27 \%$ & $99.335 .878,25$ & $-7,66 \%$ & $91.725 .087,20$ & $-9,76 \%$ \\
\hline $\begin{array}{c}\text { RECEITAS DE } \\
\text { TRANSF. }\end{array}$ & $\mathbf{1 . 9 6 4 . 0 7 8 . 5 3 9 , 2 5}$ & $\mathbf{+ 0 , 1 2 \%}$ & $\mathbf{1 . 9 6 6 . 3 5 9 . 7 8 5 , 1 4}$ & $\mathbf{- 7 , 6 0 \%}$ & $\mathbf{1 . 8 1 6 . 8 4 7 . 5 4 7 , 8 6}$ & $-\mathbf{7 , 5 0 \%}$ \\
\hline $\begin{array}{c}\text { RECEITAS } \\
\text { CORRENTES }\end{array}$ & $\mathbf{3 . 9 4 1 . 8 7 4 . 3 5 4 , 8 5}$ & $\mathbf{+ 3 , 3 4 \%}$ & $\mathbf{4 . 0 7 3 . 3 7 1 . 9 9 5 , 8 5}$ & $\mathbf{- 2 , 1 2 \%}$ & $\mathbf{3 . 9 8 6 . 8 7 0 . 9 4 6 , 1 7}$ & $+\mathbf{1 , 1 4 \%}$ \\
\hline
\end{tabular}

Fonte: Elaborado pelos próprios autores.

Os dados revelam que a arrecadação dos municípios foi afetada de forma similar aos efeitos da crise econômica. Entretanto, os comportamentos atípicos das Receitas Patrimoniais, que apresentaram crescimentos consideráveis (92,95\%), quase duplicando o montante arrecadado no período analisado.

Apesar da queda na arrecadação de receitas correntes de 2,22\% na comparação entre os anos de 2014 e 2015, destacam-se de forma individual por terem aumentado as receitas correntes apenas os seguintes municípios: São Paulo (SP), Fortaleza (CE), Cuiabá (MT) e São Caetano do Sul (SP). Por outro lado, os municípios que apresentaram o pior desempenho frente à crise foram: Betim (MG), Vitória (ES), Paraupebas (PA) e, com o pior desempenho em toda amostra, Rio das Ostras (RJ).

A definição abordada por Tristão (2013) e Orair e Alencar (2010) de preguiça fiscal não se constata nos municípios da amostra já que observando o período analisado, houve um aumento de 21,32\%, valor superior aos 5,66\% do Grupo A, o que demonstra um maior esforço fiscal por parte dos municípios de menor PIB. Apesar desse aumento substancial, a crise afetou a arrecadação de receitas próprias dos municípios, fazendo-as decrescerem em 2015 em 2,86\% em relação ao exercício anterior, efeito similar ao ocorrido no Grupo A.

Considerando as receitas correntes, constata-se que enquanto os municípios do Grupo A decresceram em 2,22\% comparando o exercício de 2015 a 2014, o Grupo B apresentou uma queda de 4,09\%. 
Tabela 4 - Análise horizontal das variações nas arrecadações dos municípios do Grupo B (Média)

\begin{tabular}{|c|c|c|c|c|c|c|}
\hline Tipo de Receita & Exercício 2013 & $\%$ & Exercício 2014 & $\%$ & Exercício 2015 & $\begin{array}{l}\text { Variaçáo \% } \\
\text { 2013-2015 } \\
\end{array}$ \\
\hline $\begin{array}{l}\text { RECEITAS } \\
\text { PRÓPRIAS }\end{array}$ & $2.179 .048,14$ & $+24,88 \%$ & $2.721 .299,67$ & $-2,86 \%$ & $2.643 .541,70$ & $+21,32 \%$ \\
\hline Receita Tributária & $1.609 .248,04$ & $+9,59 \%$ & $1.763 .615,31$ & $-1,94 \%$ & $1.729 .441,77$ & $+7,47 \%$ \\
\hline $\begin{array}{l}\text { Receita Patrimo- } \\
\text { nial }\end{array}$ & $214.038,57$ & $+49,26 \%$ & $319.483,07$ & $-5,95 \%$ & $300.460,11$ & $+40,38 \%$ \\
\hline $\begin{array}{l}\text { Receita de Ser- } \\
\text { viços }\end{array}$ & $355.761,53$ & $+79,39 \%$ & $638.201,29$ & $-3,85 \%$ & $613.639,82$ & $+72,49 \%$ \\
\hline $\begin{array}{c}\text { RECEITAS DE } \\
\text { TRANSF. }\end{array}$ & 15.646.170,94 & $+5,67 \%$ & $16.532 .729,78$ & $-4,58 \%$ & $15.775 .929,47$ & $+0,83 \%$ \\
\hline $\begin{array}{c}\text { RECEITAS } \\
\text { CORRENTES }\end{array}$ & $18.613 .686,90$ & $+7,82 \%$ & $20.069 .439,93$ & $-4,09 \%$ & $19.247 .888,12$ & $+3,41 \%$ \\
\hline
\end{tabular}

Fonte: Elaborado pelos próprios autores.

Apesar dessa queda, os municípios do Grupo B que conseguiram superar o efeito da crise econômica, arrecadando mais receitas correntes em 2015 do que no ano anterior, foram: Taipas do Tocantins (TO), Oliveira de Fátima (TO), Belém do Piauí (PI), São Miguel do Fidalgo (PI), São Félix do Tocantins (TO) e Araguainha (MT).

Outro ponto digno de nota é a arrecadação das receitas de transferências. O Grupo A apresentou uma queda de 7,5\% no período analisado, enquanto o Grupo B cresceu em $0,83 \%$. Apenas analisando a composição das receitas de transferências e como a crise a afetou para compreender essa disparidade entre os Grupos.

A análise vertical do comprometimento dos dois grupos de receita em relação às receitas correntes revela que o Grupo A e o Grupo B obtiveram uma pequena variaçáo positiva de $2 \%$ em suas receitas próprias enquanto as transferências tiveram uma queda constante (TABELA 5).

Tabela 5 - Análise vertical da contribuição para composição das receitas correntes

\begin{tabular}{c|c|c|c|c}
\hline \multirow{2}{*}{ Grupos } & Tipos de Receitas & 2013 & 2014 & 2015 \\
\hline \multirow{2}{*}{ Grupo A } & Receitas Próprias & $41 \%$ & $43 \%$ & $43 \%$ \\
\cline { 2 - 5 } & Receitas de Transferência & $50 \%$ & $48 \%$ & $46 \%$ \\
\hline \multirow{2}{*}{ Grupo B } & Receitas Próprias & $12 \%$ & $14 \%$ & $14 \%$ \\
\cline { 2 - 5 } & Receitas de Transferência & $84 \%$ & $82 \%$ & $82 \%$ \\
\hline
\end{tabular}

Fonte: Elaborado pelos próprios autores.

Esta variação positiva contraria o que alguns estudos antecipariam (VESCOVI JÚNIOR, 2003; NASCIMENTO, 2010; TRISTÃO, 2013; MASSARDI; ABRANTES, 2016) enquanto à denominada preguiça fiscal. 


\section{Conclusóes}

O presente estudo objetivou verificar a composição das receitas arrecadadas pelos municípios brasileiros e como a recente crise econômica afetou o recolhimento dos recursos públicos próprios e de transferências.

Quantoà composição das receitas arrecadadas, confirmou-se o que os estudos anteriores demonstraram: municípios com menor PIB de fato tendem a depender principalmente das receitas de transferências - cerca de $82 \%$ atualmente - enquanto os municípios de maior PIB tendem a depender igualmente das receitas próprias e de transferência. Também se observou que quanto mais habitantes possui um município, aumenta sua tendência a depender menos de receitas de transferências.

Embora a recessão econômica tenha provocado dificuldades nas gestóes de recursos públicos dos municípios brasileiros recentemente, percebeu-se que os pequenos municípios se esforçaram para aumentar suas receitas próprias, ao contrário do que a literatura previa, sendo o ponto que apresentou maior crescimento no período analisado $(21,32 \%)$. Por outro lado, o ponto que apresentou maior decréscimo de arrecadação, sendo o único que observou queda ao comparar o exercício de 2013 com 2015, foram as receitas de transferências dos municípios de maior PIB, o que demonstra, na verdade, uma maior sensibilidade desse grupo às suas variaçóes.

Vale salientar que, apesar dos esforços empregados pelas prefeituras em garantir uma arrecadação no mínimo igual aos anos anteriores, elas não foram suficientes, tendo em vista que ambos os grupos apresentaram receitas correntes inferiores em 2015 ao se comparar com o exercício anterior, demonstrando que a crise econômica de fato prejudicou a arrecadação.

Entretanto, é válido ressaltar que na amostra, 11\% dos municípios conseguiram superar os efeitos da crise econômica, arrecadando mais receitas correntes em 2015 na comparação com o exercício anterior, casos esses que merecem análise específica para compreensão das medidas adotadas que podem servir de benchmarking para as demais gestões municipais brasileiras.

Sugere-se para pesquisas futuras realizar estudos de casos para compreender a realidade dos municípios brasileiros e compreender que açôes estão sendo desenvolvidos em termos de políticas públicas para enfrentar as condiçóes econômicas adversas.

\section{Referências}

\section{AYER, Flávia. Prefeitos de Minas pedem Socorro para pagar o $13^{\circ}$ salário aos}

servidores. Disponível em: <https://www.em.com.br/app/noticia/politica/2017/11/07/ interna_politica,914595/prefeitos-de-minas-pedem-socorro-para-pagar-13-salario-aosservidores.shtml>. Acesso em: 25 jan. 2018.

BOHTE, J. School bureaucracy and student performance at the local level. Public Administration Review, v. 61, n. 1, p.92-99, 2001. 
CASELLA, G.; BERGER, R. L. Inferência estatística. 2a ed. Boston: Centage Learning, 2010.

COSSÍO, F. A. B. Disparidades econômicas inter-regionais, capacidade de obtenção de recursos tributários, esforço fiscal e gasto público no federalismo brasileiro. 1995. 134 f.Dissertação (Mestrado em Economia) - Departamento de Economia, Pontifícia Universidade Católica, Rio de Janeiro, 1995.

DANDA, G. N.; QUEIROZ, L. de F. N. de; HOFFMAN, V. E. A hélice do poder público: padróes de distribuição de recursos federais para as Fundaçóes de Amparo à Pesquisas Estaduais. Revista de Administração Pública, v. 50, n. 5, p. 843-865, 2016.

GOMES, R. C.; ALFINITO, S.; ALBUQUERQUE, P. H. M. Analyzing local government financial performance: evidence from brazilian municipalities 2005-2008. Revista de Administração Contemporânea, v. 17, n. 6,p. 704-719, 2013.

HAIR, J. F; BABIN, B; MONEY, A. H; SAMUEL, P. Fundamentos e métodos de pesquisa em administraçáo. Porto Alegre: Bookman, 2005.

MASSARDI, W. de O.; ABRANTES, L. A. Dependência dos Municípios de Minas Gerais em relação ao FPM. Revista de Gestáo, Finanças e Contabilidade, v. 6, n. 1, p. 173-187, 2016.

MASSARDI, W. de O.; ABRANTES, L. A. Esforço fiscal, dependência do FPM e desenvolvimento socioeconômico: um estudo aplicado aos municípios de Minas Gerais. Revista de Gestáo, v. 22, n. 3,p. 295-313, 2015.

MATTOS, E.; ROCHA, F.; ARVATE, P. Flypaper effect revisited: evidence for tax collection efficiency in Brazilian municipalities. Estudos Econômicos, v. 41, n. 2, p. 239$267,2011$.

MOGUES, T.; BENIN, S. Do external grants to district governments discourage own revenue generation? A look at local public finance dynamics in Ghana. World Development, v. 40, n. 5, p. 1054-1067, 2012.

MOURITZEN, P. E.; SVARA, J. H. Leadership at the Apex: politicians and administrators in western local governments. Pittsburgh: University of Pittsburgh Press, 2002.

NASCIMENTO, J. S. Efeito das transferências financeiras sobre os gastos e a arrecadaçáo dos municípios brasileiros. 2010. 181 f.Tese (Doutorado em Economia Aplicada) - Departamento de Economia, Universidade Federal de Viçosa, Viçosa,2010.

ORAIR, R. O.; ALENCAR, A. A. Esforço fiscal dos municípios: indicadores de condicionalidades para o sistema de transferências intergovernamentais. 
Disponível em: <http://www3.tesouro.fazenda.gov.br/Premio_TN/XVPremio/ financas/1tefpXVPTN/Tema_4_1.pdf>. Acesso em: 20 mar. 2017.

PIRES, M. C. C. Política econômica e estabilização: uma breve análise da recessão brasileira. Brazilian Keynesian Review, v. 2, n. 2, p. 247-251, 2016.

RAUPP, F.M.; BEUREN, I. M. Metodologia da pesquisa aplicável às ciências sociais. In. BEUREN, I.M. (Org.). Como elaborar trabalhos monográficos em contabilidade: teoria e prática. 3.ed. São Paulo: Atlas, 2006. Cap.3, p.76-97.

RIBEIRO, E. P.; SHIKIDA, C. J. Existe trade-off entre receitas próprias e transferências? O caso dos municípios mineiros. In: SEMINÁRIO SOBRE A ECONOMIA MINEIRA, 9., 2000, Diamantina. Anais... Diamantina: CEDEPLAR, 2000.

RODRIGUES, M. da P. Esforço fiscal próprio dos municípios catarinenses e transferências intergovernamentais. 2004. 64 f. Dissertação (Mestrado em Economia) Universidade Federal de Santa Catarina, Florianópolis, 2004.

SECRETARIA DO TESOURO NACIONAL. Sistema de Informaçóes Contábeis e Fiscais do Setor Público Brasileiro. Disponível em: <https://siconfi.tesouro.gov.br/siconfi/ index.jsf>. Acesso em: 20 mar. 2017.

SELCHER, W. A. The politics of decentralized federalism, national diversification, and regionalism in Brazil. Journal of Interamerican Studies and World Affairs, v. 40, n. 4, p. 25-50, 1998.

SIQUEIRA, K. J. da S. P. de. Esforço fiscal dos municípios pernambucanos: uma análise da fronteira estocástica. 2014. 67 f. Dissertação (Mestrado em Economia). Universidade Federal de Pernambuco, Recife. 2014.

SOUZA, T. O. G. de; REGO, R. B. Produção de veículos no Brasil em tempos de recessão econômica: uma análise da demanda. Relatórios de Pesquisa em Engenharia de Produçáo, v. 16, n. 1, p. 135-150, 2016.

TRISTÃO, J. A. M. A administração tributária dos municípios brasileiros: uma avaliação do desempenho da arrecadaçáo. 2003. $181 \mathrm{f}$. Tese (Doutorado em Administração) - Escola de Administração de Empresas de São Paulo, Fundação Getúlio Vargas, São Paulo. 2003.

VESCOVI JÚNIOR, J. Perfil da Administração Tributária em Municípios com até 30.000 habitantes: esforço fiscal e viabilidade municipal.2003. 105 f. Dissertação (Mestrado em Administração Pública e Governo). Fundação Getúlio Vargas, São Paulo, SP, Brasil.

WATTS, R. L. Federalism, federal political systems and federations. Annual Review of Political Science, v. 1, n. 117-137, 1998. 